\title{
FATORES QUE IMPACTAM O DESEMPENHO LOGÍSTICO E SUAS RELAÇÕES COM OS ASPECTOS ECONÔMICOS E SOCIOCULTURAIS
}

\begin{abstract}
FACTORS THAT IMPACT LOGISTIC PERFORMANCE AND ITS RELATIONSHIPS WITH ECONOMIC AND SOCIOCULTURAL ASPECTS
\end{abstract}

\section{Luiz Kennedy Cruz Machado}

luizken@yahoo.com.br

Programa de Pós-Graduação em Administração/Universidade Federal de Lavras - Lavras/Minas Gerais, Brasil $\underline{0000-0002-1090-8245}$

\section{Antônio Carlos dos Santos}

acsantos@,ufla.br

Programa de Pós-Graduação em Administração/Universidade Federal de Lavras - Lavras/Minas Gerais, Brasil $\underline{0000-0002-7499-5034}$

\section{Resumo}

Este trabalho verificou como a estabilidade política e os custos na prestação de serviços causam impacto sobre o desempenho logístico e se este interfere nos fatores econômicos e socioculturais dos países. Foi utilizado a Modelagem de Equações Estruturais (SEM-PLS) para análise dos dados, com uma amostra de 162 países considerados do ano de 2005 a 2018. Os resultados indicam que fatores políticos e de custos interferem diretamente no desempenho logístico dos países. Também se constatou que o bom desempenho das prestadoras de serviços logísticos contribui para uma melhora dos fatores econômicos e socioculturais dos países.

Palavras-chave: Desempenho logístico. Fatores econômicos e socioculturais. Modelagem de equações estruturais.

\begin{abstract}
This work verified how political stability and costs in the provision of services impact on logistical performance and if it interferes with the economic and socio-cultural factors of the countries. Structural Equation Modeling (SEM-PLS) was used to analyze the data, with a sample of 162 countries considered from 2005 to 2018. The results indicate that political and cost factors directly interfere in the countries' logistical performance. It was also found that the good performance of the logistics service providers contributes to an improvement in the economic and socio-cultural factors of the countries.
\end{abstract}

Keywords: Logistic performance. Economic and sociocultural factors. Structural equation modelling. 


\section{Introdução}

A alta competitividade dos últimos anos deixa o mercado dinâmico, instável e em constante evolução. A análise de seu desempenho se torna imprescindível para a sobrevivência das organizações e pode gerar uma vantagem competitiva por meio da compreensão do cenário em que a organização está inserida.

As mudanças nos fluxos comerciais das últimas décadas intensificaram e aproximaram as relações políticas e sociais entre os países. Estudar essas relações torna-se um fator fundamental nos tempos atuais, uma vez que elas interferem no crescimento econômico que remete a expansão da produção.

Aportes na infraestrutura promovem diretamente o crescimento econômico dos países (CARLSSON; OTTO; HALL, 2013). O setor logístico impacta nessas relações e na vantagem competitiva dos países, sendo que uma compreensão do desempenho logístico pode mostrar as vantagens e pontos mais vulneráveis em uma negociação internacional. Seu ambiente é afetado por questões políticas, econômicas, sociais e tecnológicas.

O desempenho logístico é relacionado com a confiabilidade das cadeias de suprimento e à previsibilidade da entrega do serviço pelos produtores e exportadores (ARVIS et al., 2014). Seus indicadores são fundamentais para analisar a competitividade entre os países, uma vez que englobam questões relacionadas a adoção de uma estratégia para competir, além de fatores como infraestrutura, custos e melhorias por meio da inovação (BAZANI, 2017).

A avaliação operacional de sistemas logísticos pode ser gerada por indicadores de desempenho. Esses indicadores atuam como "termômetro" na busca dos objetivos traçados pelo planejamento estratégico, uma vez que auxiliam no controle da performance de fatores ligados as atividades logísticas da empresa ou de seus parceiros.

Os indicadores de desempenho logístico refletem os resultados da organização ou do país, tanto nas questões internas como nas externas relacionadas a atuação no cenário nacional e internacional. Um conjunto de indicadores amplo e bem estabelecido é fundamental para enfrentar as ameaças e oportunidades presentes no ambiente competitivo (GOMES; RIBEIRO, 2004).

Porém, a relação com o mercado acarreta em custos, também chamados de custos de transação, que são resultados de eventos e variam de uma negociação para outra, envolvendo o perfil dos negociantes, cultura, competitividade do mercado, oferta, demanda, leis, entre outros fatores. Claramente esses custos se relacionam com os custos logísticos, visto que esse advém quando a empresa recorre ao mercado.

A Nova Economia Institucional (NEI) é uma corrente teórica que analisa esses custos de transação por diferentes perspectivas dentro de um ambiente. Ela busca compreender os motivos das empresas se organizarem em arranjos interorganizacionais e no entendimento de suas estruturas de governanças como elemento fundamental na busca por um desempenho competitivo.

Fatores políticos, geográficos, econômicos, culturais e sociais moldam um ambiente de negócios complexo que afeta a negociação entre os países e gera custos entre as transações. A NEI fornece um aporte teórico consistente na discussão desses fatores e de suas interações.

Diante desses fatos, esse trabalho tem como objetivo verificar como a estabilidade política e os custos na prestação de serviços causam impacto sobre o desempenho logístico e se este interfere nos fatores econômicos e socioculturais dos países.

O presente artigo está estruturado em cinco seções, a contar esta introdução. No tópico seguinte apresenta-se o referencial teórico sobre a logística organizacional e seus indicadores de desempenho, seguida pela Nova Economia Institucional com destaque nos custos de transação. Adiante está o percurso 
metodológico utilizado nesta pesquisa, seguido dos resultados e discussão. Por fim, são apresentadas as conclusões e as referências bibliográficas.

\section{Logística e seus indicadores de desempenho}

O Council of Supply Chain Management Professionals (CSCMP) propôs o conceito de logística como a parte da cadeia de suprimentos que planeja, implementa e controla, de modo eficiente e eficaz, o fluxo direto e reverso e a armazenagem de bens, serviços e informações relativas desde o ponto de origem até o ponto de consumo de modo a atender os requisitos dos clientes (CSCMP, 2009).

Sistemas integrados e a redução de custos são elementos fundamentais às estratégias logísticas. Kobayashi, (2000) afirma que os componentes que estruturam um sistema logístico e sua eficiência são provenientes da particularidade de cada país, como seus fatores geográficos, sua organização políticosocial e o próprio ambiente natural da região.

Kobayashi (2000) sinaliza que para administrar as atividades logísticas deve-se haver o uso de indicadores relativos aos custos, serviços e todas as atividades que perpassam o setor. Os indicadores logísticos devem compreender elementos que contribuam com a competividade da organização, que relacione os custos, a produtividade, a qualidade e o tempo (REY, 1999).

Para Bazani (2017), o desempenho logístico reflete os resultados da organização, tanto nos quesitos internos como nos externos relacionados a atuação no cenário nacional e internacional. Os indicadores de desempenho logístico merecem atenção dos agentes exportadores e importadores, além das agências governamentais que atuam nesse cenário institucional.

Diante dessas questões e da complexidade em realizar comparações entre países para identificar os principais entraves logísticos para a promoção do comércio internacional, o Banco Mundial começou a publicar no ano de 2007 um relatório intitulado Connecting to Compete, com sua segunda edição publicada em 2010 e a partir desse ano com publicação bianual (2012, 2014, 2016, 2018).

Esse relatório fornece um ranking de desempenho logístico nacional e internacional (foco desse trabalho), a partir da criação de um Índice de Desempenho Logístico, do inglês Logistic Performance Index (LPI). O LPI objetiva sintetizar o desempenho logístico de mais de 160 países por meio de seis indicadores que representam diferentes dimensões do processo logístico e forma um índice geral, são eles: alfândega; infraestrutura; carregamentos internacionais (criado em 2010, antes era representado pelos indicadores facilidade de carregamento e custos logísticos domésticos); qualidade e competência logística; monitoramento e rastreabilidade; e previsibilidade (BANCO MUNDIAL, 2018).

O LPI é um índice que utiliza uma técnica estatística padrão para diminuir a dimensão de um conjunto de dados, nomeada de análise de componentes principais (PCA). Os indicadores formam o índice geral e cada um deles tem um peso aproximado de 0,41 nessa composição geral (BANCO MUNDIAL, 2018).

Certamente as dimensões logísticas têm relações entre elas. O Banco Mundial (2018) considera que os indicadores ligados a ações políticas estão relacionados às entradas da cadeia de suprimento, sendo eles os indicadores alfândega, infraestrutura e qualidade e competência logística. Já os resultados (saídas), que compõem a mensuração do desempenho da gestão da cadeia de suprimentos, são formados pelos indicadores de carregamentos internacionais, monitoramento e rastreabilidade e previsibilidade.

As características de cada um dos indicadores são:

Alfândega: mensura a eficiência da gestão aduaneira e das fronteiras de liberação. Esse indicador de desempenho aborda a eficiência das atividades aduaneiras de rotina, procedimentos de desembaraço aduaneiro tais como: inspeção física, apresentação eletrônica, liberação antes e após a chegada, auditoria e transparência dos procedimentos alfandegários e administrativos (FATTIBENE et al., 2012). 
Infraestrutura: remete a qualidade da infraestrutura relacionada ao comércio e transporte de mercadorias. Para Soliani (2018), esse indicador interfere diretamente no fluxo dos processos de comércio internacional. Os custos de transporte, o desempenho das exportações e os fluxos de comércio geralmente dependem da qualidade e infraestrutura institucional.

Qualidade e competência logística: Envolve a atividade de operadores de transporte em todos os modais, despachantes aduaneiros e serviços de expedição em geral, tanto de fornecedores públicos como privados (BANCO MUNDIAL, 2018).

Carregamentos internacionais: analisa a facilidade de organizar remessas com preços competitivos. Avalia a capacidade de preparar o embarque e desembarque de modo eficiente, flexível, previsível e a preços competitivos (BANCO MUNDIAL, 2018).

Monitoramento e rastreamento: como o próprio nome diz, envolve o controle das mercadorias por meio do monitoramento e rastreamento, desde seu local de origem até o ponto de entrega, ressaltando as alterações de rotas e datas que podem ocorrer durante o processo (BANCO MUNDIAL, 2016).

Previsibilidade: para o Banco Mundial (2018), esse indicador avalia a frequência com que as remessas chegam aos consignatários dentro do prazo de entrega programado ou esperado. Faria, Souza e Vieira (2015) entendem que a necessidade de inspeções físicas, tecnologias obsoletas e uma infraestrutura de transporte ineficiente, podem contribuir para um baixo índice nesse indicador.

Faria, Souza e Vieira (2015) dizem que a partir dos indicadores do LPI é possível identificar as deficiências e desafios logísticos que os países enfrentam ao transacionar com o mercado externo. Martí, Puertas e García (2014) concluíram que qualquer um dos seis indicadores do LPI contribui para o crescimento significativo dos fluxos de comércio. Eles analisaram, por meio de um modelo gravitacional, o impacto que cada um dos indicadores tem no comércio de países emergentes situados na África, América do Sul e Leste Europeu, e o avanço do setor logístico nesses países.

Kabak, Ülengin e Ekici (2018) analisaram as relações entre os seis indicadores que compõem o LPI de 2016 com as exportações de países em diferentes situações no comércio internacional, como Brasil, Portugal, Turquia, Zimbábue e Burundi. O trabalho constatou que o Brasil necessita melhorar todos os indicadores que compõem o índice para obter um alto desempenho em exportações, com ponto crítico nos indicadores de alfândega e previsibilidade.

O desempenho da logística brasileira é trabalhado na pesquisa de Mariano et al. (2017). O LPI de 2014 é relacionado com as emissões de CO2 (dióxido de carbono) do setor de transporte, sendo proposto por meio da metodologia de análise envoltória de dados (DEA), um índice para desempenho logístico com baixa emissão de carbono. Os resultados apresentaram o Brasil na $25^{a}$ posição desse ranking, sendo Luxemburgo, Irlanda e Honduras os três primeiros, nessa ordem.

\section{Nova Economia Institucional (NEI) e os custos de transacionar com o mercado}

A NEI estuda as instituições que são compostas por regras, normas e restrições que os homens criam para reduzir a incerteza e controle do seu ambiente e a forma pela qual elas interagem com os arranjos organizacionais. A NEI auxilia na identificação da melhor forma de estabelecer as transações econômicas. Essa corrente teórica envolve um nexo de conceitos mais condizentes com a atual estrutura de governança das organizações, se empenha em explicar as diferentes formas organizacionais que acontecem no mercado e foca no ambiente institucional e sua interação com as organizações (JOSKOW, 1995).

Para Frainer (2010), a NEI abdica o padrão neoclássico nas hipóteses de que os indivíduos têm perfeita informação e racionalidade substantiva, assumindo que as transações não ocorrem de forma instantânea 
e sem custo. De modo oposto, a NEI assume que os indivíduos têm informação incompleta e capacidade mental limitada e, por causa de sua incerteza, incorre em custos para adquirir essa informação.

Para a NEI, o mundo das organizações e instituições econômicas são vistas por meio de um corte analítico que foca no estudo da eficiência das relações contratuais intra e entre organizações (COASE, 1937; CUNHA; SAES; MAINVILLE, 2015; WATANABE, 2007; ZYLBERSZTAJN, 1995).

O objetivo fundamental da NEI, segundo Zylbersztajn (1995), é o estudo dos custos das transações como $\mathrm{o}$ indutor das diferentes formas de organização da produção, dentro de um ambiente institucional. Para o autor a transação é a principal variável de análise, em que são negociados direitos de propriedade.

A Teoria dos Custos de Transação (TCT), uma das vertentes básicas da NEI, contribui para a compreensão de os motivos das firmas estarem se organizando em múltiplos arranjos interorganizacionais e na compreensão da complexidade dos seus arranjos contratuais. A estrutura de governança das firmas é um elemento fundamental na busca por um desempenho corporativo satisfatório. A TCT foi o ponto de partida da Nova Economia Institucional (NEI), criada inicialmente por Ronald Coase $(1937,1960)$ e consolidada por meio dos trabalhos de Oliver Williamson $(1975,1985$, 1989, 1991 e 1993) no qual estuda as instituições e suas formas de interações com as organizações.

Williamson (2000) apresenta o ambiente institucional como um influenciador nas estruturas de governanças e, continuamente, na designação de recursos econômicos. Os fatores institucionais, segundo Boehe e Zawislak (2007), podem influenciar as mudanças organizacionais de três formas distintas: incentivando a concorrência de mercado; por meio de regras governamentais; e pelos custos relativos.

Questões que dificulta uma maior frequência nas transações podem ser consideradas como fonte de custos de transação. A frequência é fundamental para se atingir economias de escala e de escopo nas transações, que além de diminuir os custos de transação, reduz os custos de produção (WILLIAMSON, 1985). Para Zylbersztajn (1995), a frequência na qual as transações ocorrem é importante para determinar a possibilidade de internalizar uma determinada etapa produtiva sem perder eficiência relacionada à escala, e também está fortemente associada à determinação da importância dos atores que participam da transação.

No que tange à especificidade dos ativos, esse termo refere-se a maior ou menor possibilidade de utilização alternativa de um ativo e os custos envolvidos neste processo. Em outras palavras, é o quanto o investimento no ativo é específico para a atividade e quão custoso é sua utilização alternativa em outra situação (WILLIAMSON, 1985). Diante disso, Arbage (2004) cita um aspecto importante que merece atenção: quanto maior a especificidade de um ativo dedicado à produção, menor tende a ser a possibilidade de utilização alternativa do mesmo e maiores os custos envolvidos nesta transação.

Neste contexto surge a elaboração de contratos complexos se torna obviamente imperfeita nesse ambiente de racionalidade limitada, o que cria a necessidade de realizar adaptações e correções diante dos possíveis imprevistos que surgem em função de lacunas contratuais não abordadas ou antecipadas pelo contrato firmado originalmente. Tais lacunas podem ser exploradas de maneira oportunista pela contraparte e vir a provocar falhas de mercado e custos de transação (WILLIAMSON, 2007), o que está propenso a ocorrer nos negócios cercados por incertezas.

As incertezas provenientes do mercado não permitem que os agentes criem cláusulas contratuais que associem os resultados futuros do contrato com a realidade futura do mercado (ROCHA JUNIOR et al., 2008). Os nexos de contratos surgem como alternativas para minimizar os riscos das transações e que pode ser feito internamente na empresa ou entre organizações. Quanto mais próximo da perfeição for um contrato, mais eficiente serão seus resultados, e caso contrário, uma parte pode atuar oportunisticamente mascarando os resultados e agindo em interesse próprio (DAGDEVIREN; ROBERTSON, 2013). 
Em um panorama recente, Argyres, Mahoney e Nickerson (2019) exploram o papel dos custos de ajustes comparativos na determinação da vantagem competitiva em ambientes dinâmicos, no qual os autores se fundamentam nas contribuições de Penrose, Porter e Williamson para conceituar a relação entre os custos de ajustes com as capacidades dinâmicas, custos de transação e de oportunidade.

No que tange os contratos, Garaffa et al. (2019) pesquisam os contratos de longo prazo indexados ao preço do petróleo, sendo uma característica básica para a evolução da indústria europeia de gás natural. O trabalho testa a hipótese de que respostas assimétricas de preços nos contratos da Europa continental derivam dos custos de transação. Foram aplicados modelos de correção de erros lineares e não lineares e os resultados mostraram um alto grau de integração entre a Alemanha, Bélgica e Holanda, com os preços convergindo para um equilíbrio de longo prazo, porém os ajustes de preços assimétricos revelam a presença de custos de transação nos contratos regionais da Alemanha.

Os custos de transação também se relacionam diretamente com os custos logísticos, visto que esse advém quando a empresa recorre ao mercado. Limão e Venables (2001) analisam os dados de um comércio bilateral e demonstram a importância da infraestrutura como determinante nos custos de transporte, enquanto Bougheas, Demetriades e Morgenroth (1999) mediram o impacto da infraestrutura nos custos de transporte no comércio de países europeus. Os autores concluem que os custos de transporte são inversamente ao nível de infraestrutura e há uma relação direta e positiva entre o nível de infraestrutura e o volume de comércio.

\section{Procedimentos metodológicos}

Para verificar como a estabilidade política e os custos na prestação de serviços causam impacto sobre o desempenho logístico e se estes interferem nos fatores econômicos e socioculturais dos países, foi utilizado a Modelagem de Equações Estruturais por Mínimos Quadrados Parciais, do inglês Structural Equation Modelling, Partial Least Squares - SEM-PLS, a luz da Nova Economia Institucional.

O Banco Mundial associa os seis indicadores que formam o LPI geral, a dois constructos, sendo eles as "Regulações Políticas" e o "Desempenho na Prestação de Serviços".

Foram propostos quatro outros constructos para mensurar se a "Estabilidade Política" e os "Custos na Prestação de Serviçoo" impactam nos constructos do LPI, e se esses dois impactam nos "Fatores Econômicos" e nos "Fatores Socioculturais" dos países. As hipóteses para testar as relações entre os constructos são expostas no Quadro 1.

Quadro 1 - Hipóteses da pesquisa e seus resultados esperados.

\begin{tabular}{|clc|}
\hline Hipótese & \multicolumn{1}{c|}{ Relação } & $\begin{array}{c}\text { Relação } \\
\text { Esperada }\end{array}$ \\
\hline $\mathrm{H}_{1}$ & A Estabilidade Política influencia de forma positiva as Regulações Políticas dos países. & + \\
\hline $\mathrm{H}_{2}$ & A Estabilidade Política influencia de forma positiva o Desempenho na Prestação dos Serviços. & + \\
\hline $\mathrm{H}_{3}$ & Os Custos na Prestação de Serviços impactam negativamente nas Regulações Políticas. & - \\
\hline $\mathrm{H}_{4}$ & $\begin{array}{l}\text { Os Custos na Prestação de Serviços impactam negativamente o Desempenho na Prestação } \\
\text { dos Serviços. }\end{array}$ & - \\
\hline $\mathrm{H}_{5}$ & As Regulações Políticas influenciam de forma positiva os Fatores Econômicos. & + \\
\hline $\mathrm{H}_{6}$ & As Regulações Políticas influenciam de forma positiva os Fatores Socioculturais. & + \\
\hline $\mathrm{H}_{7}$ & O Desempenho na Prestação de Serviços influencia positivamente os Fatores Econômicos. & + \\
\hline $\mathrm{H}_{8}$ & O Desempenho na Prestação de Serviços influencia positivamente os Fatores Socioculturais. & + \\
\hline $\mathrm{H}_{9}$ & $\begin{array}{l}\text { As Regulações Políticas influenciam de forma positiva o Desempenho na Prestação de } \\
\text { Serviços. }\end{array}$ & + \\
\hline
\end{tabular}

Fonte: Elaborada a partir dos dados da pesquisa.

Para representar o modelo estrutural por meio da Modelagem de Equação Estrutural, utilizou-se como convenção o desenho de diagramas (path model) conhecido por Diagrama de Caminho. A Figura 1 exibe 
o Modelo de Mensuração (externo) que apresenta as relações entre os construtos não observáveis, representadas por círculos, e as variáveis observáveis que estão representadas por retângulos (HAIR et al, 2016).

Figura 1 - Modelo de mensuração proposto (externo).

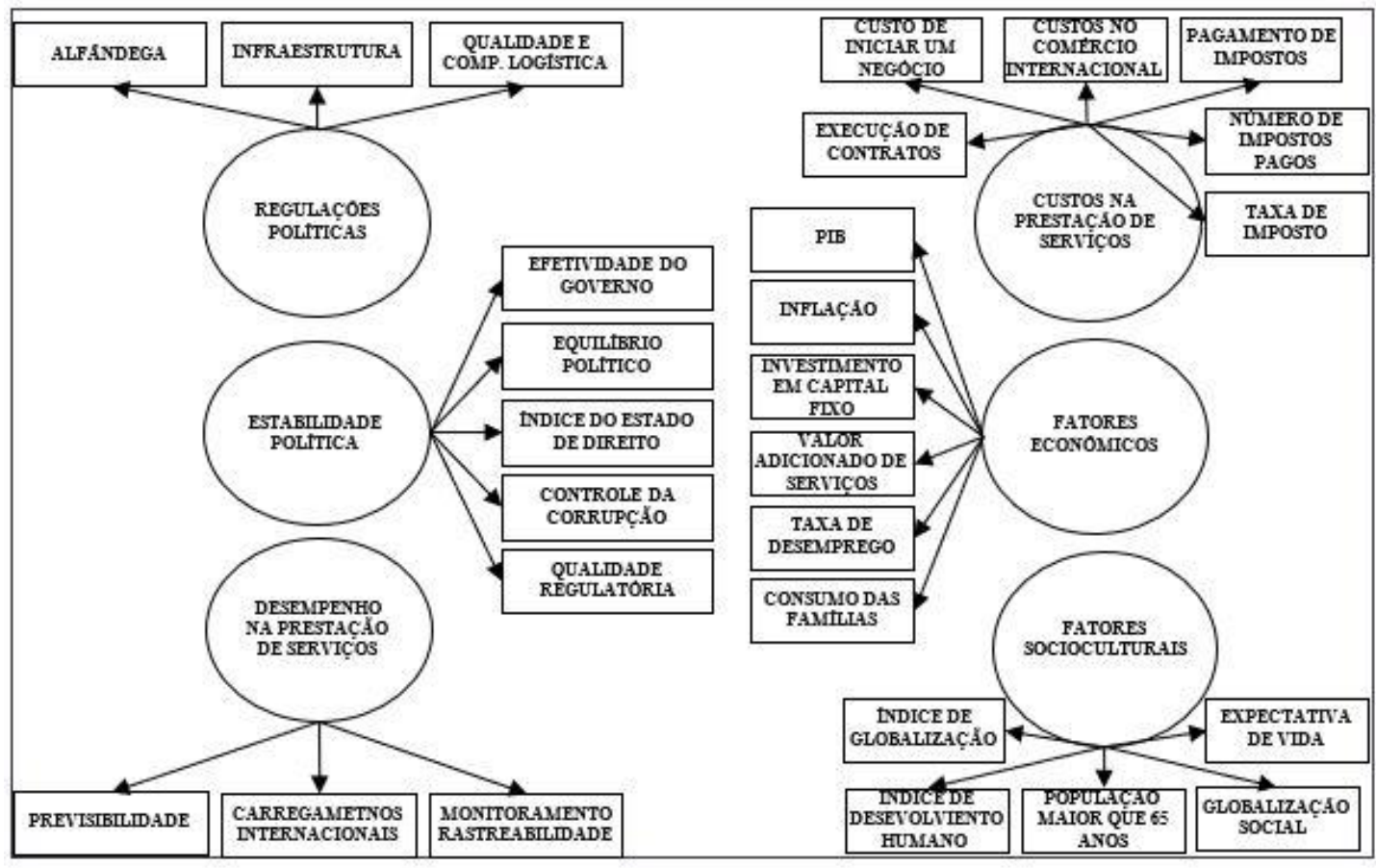

Fonte: Elaborado com base em Hair et al. (2009, 2016).

Também em relação ao Diagrama de Caminho, Hair et al. $(2009,2016)$ apresentam o Modelo Estrutural (interno), onde as relações entre os próprios construtos não observáveis são expostas e essas relações representam as hipóteses que estão sendo testadas. A Figura 2 exibe o Modelo de Mensuração da presente pesquisa.

Figura 2 - Modelo Estrutural (interno).

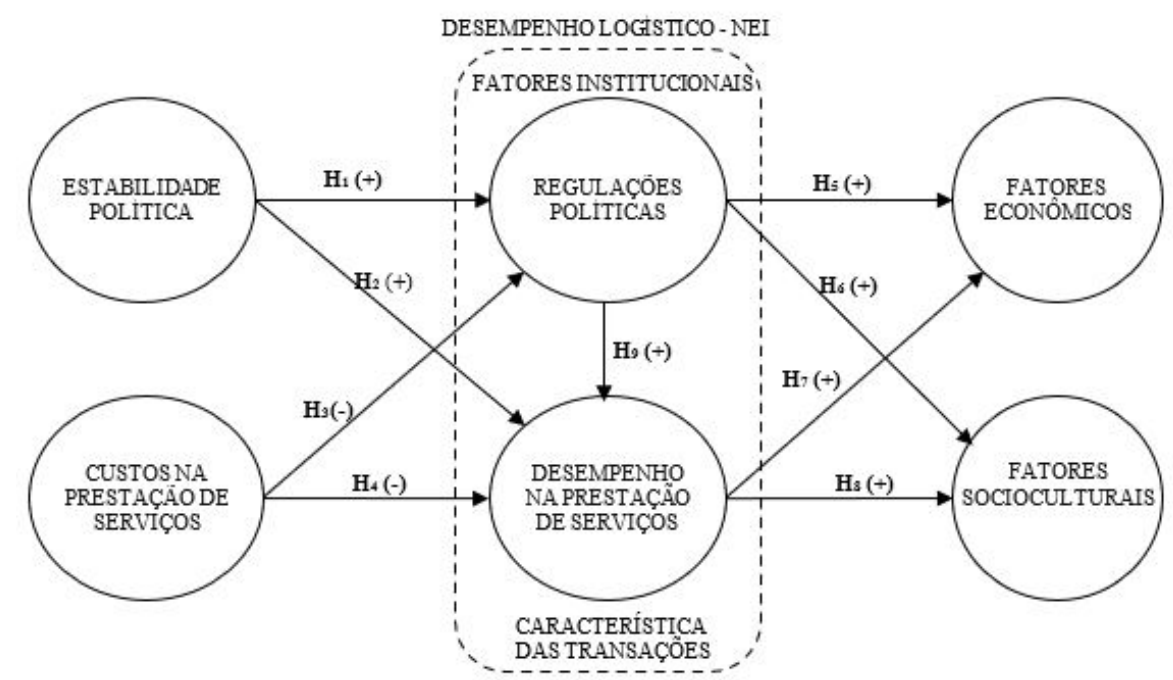

Fonte: Elaborado com base em Hair et al. (2009, 2016).

A linha pontilhada na Figura 2 sinaliza para a análise dos constructos do LPI por meio dos fatores institucionais e das características das transações da NEI. Os indicadores utilizados para representar a Estabilidade Política e os Custos na Prestação de serviços, são as variáveis exógenas (independentes) 
observadas, enquanto os indicadores utilizados para representar as Regulações Políticas, o Desempenho na Prestação de Serviços, os Fatores Econômicos e os Fatores Socioculturais, são as variáveis endógenas (dependentes) observadas no modelo proposto.

O Quadro 2 apresenta as variáveis endógenas e exógenas observadas, agrupadas por constructos, com suas respectivas siglas, significados e fontes que divulgam as informações.

Quadro 2 - Constructos e seus indicadores propostos.

\begin{tabular}{|c|c|c|c|c|}
\hline Constructo & Sigla & Variáveis & Significado & Fonte \\
\hline \multirow{5}{*}{$\begin{array}{l}\text { Estabilidade } \\
\text { Política }\end{array}$} & EfG & $\begin{array}{l}\text { Efetividade do } \\
\quad \text { Governo }\end{array}$ & $\begin{array}{c}\text { Capta as percepções da qualidade dos serviços públicos, a } \\
\text { qualidade da formulação e implementação de políticas e } \\
\text { sua credibilidade. }\end{array}$ & Banco Mundial \\
\hline & $\mathrm{CoC}$ & $\begin{array}{c}\text { Controle (Nível) } \\
\text { da Corrupção }\end{array}$ & $\begin{array}{c}\text { Capta a percepção de até que ponto o poder público é } \\
\text { exercido para ganhos privados, como formas de } \\
\text { corrupção. }\end{array}$ & Banco Mundial \\
\hline & $\mathrm{EqP}$ & $\begin{array}{l}\text { Equilíbrio } \\
\text { Político }\end{array}$ & $\begin{array}{l}\text { Mede a probabilidade de o governo ser desestabilizado ou } \\
\text { derrubado por meios inconstitucionais ou violentos. }\end{array}$ & Banco Mundial \\
\hline & IED & $\begin{array}{l}\text { Índice do Estado } \\
\text { de Direito }\end{array}$ & $\begin{array}{c}\text { Captura percepções sobre até que ponto os agentes } \\
\text { confiam e respeitam as regras da sociedade (execução de } \\
\text { contratos, direitos de propriedade, a polícia e os tribunais) }\end{array}$ & $\begin{array}{l}\text { Projeto de Justiça } \\
\text { Mundial }\end{array}$ \\
\hline & QuR & $\begin{array}{l}\text { Qualidade } \\
\text { Regulatória }\end{array}$ & $\begin{array}{l}\text { Captura a capacidade do governo de formular e } \\
\text { implementar políticas e regulamentos sólidos que } \\
\text { promovam o desenvolvimento do setor privado. }\end{array}$ & Banco Mundial \\
\hline \multirow{6}{*}{$\begin{array}{l}\text { Custos na } \\
\text { Prestação de } \\
\text { Serviços }\end{array}$} & $\mathrm{CIN}$ & $\begin{array}{l}\text { Custo de Iniciar } \\
\text { um negócio }\end{array}$ & $\begin{array}{c}\text { Inclui todas as taxas e honorários oficiais para serviços } \\
\text { legais ou profissionais, se tais serviços forem exigidos por } \\
\text { lei. }\end{array}$ & Banco Mundial \\
\hline & $\mathrm{ExC}$ & $\begin{array}{l}\text { Execução de } \\
\text { Contratos }\end{array}$ & $\begin{array}{l}\text { Avalia se a economia adota uma série de boas práticas que } \\
\text { promovem a qualidade e a eficiência dos tribunais, com } \\
\text { menor tempo e custo para resolver uma disputa comercial. }\end{array}$ & Banco Mundial \\
\hline & CCI & $\begin{array}{l}\text { Custos no } \\
\text { Comércio } \\
\text { Internacional }\end{array}$ & $\begin{array}{l}\text { Os custos e procedimentos envolvidos na importação e } \\
\text { exportação de um embarque patrocinado de mercadorias. }\end{array}$ & Banco Mundial \\
\hline & PgI & $\begin{array}{l}\text { Pagamento de } \\
\text { Imposto }\end{array}$ & $\begin{array}{c}\text { Remete aos encargos tributários que uma empresa de } \\
\text { porte médio normalmente paga ou recolhe durante o ano } \\
\text { fiscal. }\end{array}$ & Banco Mundial \\
\hline & NIP & $\begin{array}{l}\text { Número de } \\
\text { impostos pagos } \\
\text { pelas empresas }\end{array}$ & $\begin{array}{c}\text { Total de impostos pagos pelas empresas, sendo } \\
\text { contabilizado como pago uma vez por ano, mesmo que os } \\
\text { pagamentos sejam mais frequentes. }\end{array}$ & Banco Mundial \\
\hline & TxI & $\begin{array}{c}\text { Taxa de imposto } \\
-\% \text { de lucros } \\
\text { comerciais } \\
\end{array}$ & $\begin{array}{l}\text { Mede o valor dos impostos e contribuições obrigatórias a } \\
\text { serem pagos pelas empresas após contabilizar deduções e } \\
\text { isenções permitidas como parcela dos lucros comerciais. }\end{array}$ & Banco Mundial \\
\hline \multirow{3}{*}{$\begin{array}{l}\text { Regulações } \\
\text { Políticas }\end{array}$} & Alf & Alfândega & $\begin{array}{l}\text { Mensura a eficiência da gestão aduaneira e das fronteiras } \\
\text { de liberação }\end{array}$ & $\begin{array}{l}\text { Banco Mundial - } \\
\text { LPI }\end{array}$ \\
\hline & Inf & Infraestrutura & $\begin{array}{l}\text { Remete a qualidade da infraestrutura para o comércio e } \\
\text { transporte de mercadorias. }\end{array}$ & $\begin{array}{l}\text { Banco Mundial - } \\
\text { LPI }\end{array}$ \\
\hline & QCL & $\begin{array}{c}\text { Qualidade e } \\
\text { Comp. Logística. }\end{array}$ & $\begin{array}{l}\text { Envolve atividade de operadores de transporte, } \\
\text { despachantes aduaneiros e serviços de expedição. }\end{array}$ & $\begin{array}{l}\text { Banco Mundial - } \\
\text { LPI }\end{array}$ \\
\hline \multirow{3}{*}{$\begin{array}{l}\text { Desempenho } \\
\text { na Prestação de } \\
\text { Serviços }\end{array}$} & Pre & Previsibilidade & $\begin{array}{l}\text { Avalia a frequência com que as remessas chegam aos } \\
\text { consignatários dentro dos prazos de entrega. }\end{array}$ & $\begin{array}{l}\text { Banco Mundial - } \\
\text { LPI }\end{array}$ \\
\hline & $\mathrm{CaI}$ & $\begin{array}{l}\text { Carregamentos } \\
\text { Internacionais }\end{array}$ & $\begin{array}{c}\text { Avalia a capacidade de preparar o embarque e } \\
\text { desembarque de modo eficiente, flexível, previsível e a } \\
\text { preços competitivos. }\end{array}$ & $\begin{array}{l}\text { Banco Mundial - } \\
\text { LPI }\end{array}$ \\
\hline & MoR & $\begin{array}{l}\text { Monitoramento e } \\
\text { Rastreabilidade }\end{array}$ & $\begin{array}{c}\text { Envolve o controle das mercadorias por meio do } \\
\text { monitoramento e rastreamento, do local de origem ao } \\
\text { ponto de entrega. }\end{array}$ & $\begin{array}{c}\text { Banco Mundial - } \\
\text { LPI }\end{array}$ \\
\hline $\begin{array}{c}\text { Fatores } \\
\text { Econômicos }\end{array}$ & PIB & $\begin{array}{c}\text { Produto Interno } \\
\text { Bruto }\end{array}$ & $\begin{array}{l}\text { Soma do valor bruto acrescentado de todos os produtores } \\
\text { residentes na economia mais impostos sobre produtos e } \\
\text { menos subsídios não incluídos no valor dos produtos. }\end{array}$ & Banco Mundial \\
\hline
\end{tabular}




\begin{tabular}{|c|c|c|c|c|}
\hline & $\operatorname{Inf}$ & Inflação & $\begin{array}{c}\text { Reflete a variação percentual anual do custo para o } \\
\text { consumidor médio da aquisição de uma cesta de bens e } \\
\text { serviços }\end{array}$ & Banco Mundial \\
\hline & ICF & $\begin{array}{l}\text { Investimento em } \\
\text { Capital Fixo }\end{array}$ & $\begin{array}{l}\text { Consiste em despesas com adições aos ativos fixos mais } \\
\text { variações líquidas no nível de estoques. }\end{array}$ & Banco Mundial \\
\hline & VAS & $\begin{array}{l}\text { Valor Adicionado } \\
\text { de Serviço }\end{array}$ & $\begin{array}{c}\text { Incluem valor agregado no comércio atacadista e varejista, } \\
\text { transporte e serviços governamentais, financeiros e } \\
\text { pessoais. }\end{array}$ & Banco Mundial \\
\hline & $\mathrm{TxD}$ & $\begin{array}{c}\text { Taxa de } \\
\text { Desemprego }\end{array}$ & $\begin{array}{c}\text { Refere-se à força de trabalho que está sem trabalho, mas } \\
\text { disponível para procurar emprego. }\end{array}$ & Banco Mundial \\
\hline & $\mathrm{CoF}$ & $\begin{array}{l}\text { Consumo das } \\
\text { Famílias }\end{array}$ & $\begin{array}{l}\text { Valor de mercado de todos os bens e serviços, incluindo } \\
\text { produtos duráveis. }\end{array}$ & Banco Mundial \\
\hline \multirow{5}{*}{$\begin{array}{l}\text { Fatores } \\
\text { Socioculturais }\end{array}$} & $\mathrm{IDH}$ & $\begin{array}{c}\text { Índice de } \\
\text { Desenvolvimento } \\
\text { Humano }\end{array}$ & $\begin{array}{l}\text { Mede três dimensões básicas do desenvolvimento } \\
\text { humano: vida longa e saudável, conhecimento e um } \\
\text { padrão de vida decente. }\end{array}$ & $\begin{array}{l}\text { Programa das } \\
\text { Nações Unidas }\end{array}$ \\
\hline & $\operatorname{InG}$ & $\begin{array}{c}\text { Índice de } \\
\text { Globalização }\end{array}$ & $\begin{array}{l}\text { Abarca as dimensões econômica, social e política da } \\
\text { globalização. Valores Altos denotam maior globalização. }\end{array}$ & $\begin{array}{l}\text { Instituto Suíço de } \\
\text { Tecnologia }\end{array}$ \\
\hline & PMA & $\begin{array}{l}\text { População maior } \\
\text { que } 65 \text { anos }(\% \\
\text { do total) }\end{array}$ & $\begin{array}{l}\text { Baseado na definição de população, que conta todos os } \\
\text { residentes, independentemente do status legal ou da } \\
\text { cidadania. }\end{array}$ & $\begin{array}{l}\text { Divisão de } \\
\text { População das } \\
\text { Nações Unidas }\end{array}$ \\
\hline & GIS & $\begin{array}{l}\text { Globalização } \\
\text { Social }\end{array}$ & $\begin{array}{l}\text { Envolve contatos pessoais, fluxos de informação e } \\
\text { proximidade cultural. }\end{array}$ & Banco Mundial \\
\hline & $\mathrm{ExV}$ & $\begin{array}{l}\text { Expectativa de } \\
\text { Vida }\end{array}$ & $\begin{array}{l}\text { Número de anos que um recém-nascido viveria se os } \\
\text { padrões de mortalidade no momento do nascimento } \\
\text { fossem os mesmos durante toda a vida. }\end{array}$ & Banco Mundial \\
\hline
\end{tabular}

Fonte: Elaborada a partir dos dados da pesquisa.

A coleta dos dados foi realizada na base de dados TheGlobalEconomy.com, com exceção dos indicadores do LPI, uma base de dados que agrupa mais de 300 indicadores de 200 países fornecidos por diversas fontes oficiais como o Banco Mundial, o Fundo Monetário Internacional, as Nações Unidas e o Fórum Econômico Mundial.

Ressalta-se que a amostra foi utilizada em corte transversal e o critério foi país/ano, inicialmente com todos os países que são analisados no índice LPI e o ano inicial foi o de 2005, dois anos antes do primeiro LPI para captar os efeitos que impactam nesse, até o ano de 2018. Esse procedimento possibilita uma expansão significativa do número de observações e permite verificar a influência da série de tempo nas análises.

A abordagem aqui apresentada possibilita gerar um modelo de análise capaz de validar o impacto da estabilidade política e dos custos na prestação de serviços, sobre os constructos do LPI à luz na NEI, e desses sobre os fatores econômicos e socioculturais dos países.

\section{Apresentação e análise dos resultados}

Os resultados estão apresentados em dois subtópicos. No primeiro deles temos os critérios de avaliação do modelo estrutural reflexivo, assim como os critérios de ajustes do modelo de equação estrutural analisado. No subtópico seguinte apresenta-se a análise do modelo, as hipóteses testadas e suas implicações.

\section{Critérios de validação do modelo}

A princípio, foram excluídas da amostra, países que possuíam dados ausentes (missings) superiores a 15\% do total de cada variável, conforme sugerem Hair et al. (2016). Os valores ausentes de cada variável, quando representavam menos de $15 \%$ do total dos dados, foram substituídos pela média de seus vizinhos diretos, ou seja, a média entre os dados do ano seguinte com o ano anterior ao dado ausente. 
No caso de o valor ausente ser o primeiro ou o último da série, seu valor foi substituído pelo vizinho direto mais o desvio padrão entre os dois próximos valores, no caso de ser o primeiro da série, ou menos no caso de ser o último valor da série.

Em relação ao LPI que possui valores divulgados de dois em dois anos (com exceção dos anos de 2007 e 2010), os anos anteriores a divulgação foram representados pelos valores do LPI seguinte, sendo a pesquisa do LPI divulgado em 2007, por exemplo, foi realizada em 2005 e 2006 segundo informações do Banco Mundial (2018) e está referente a esses anos no banco de dados. Por fim, são 162 países com variáveis coletadas de 2005 a 2018.

Algumas variáveis não representativas e que não se ajustaram ao modelo proposto foram excluídas, segundo os critérios utilizados por Hair et al. (2016) e Guedes Neto et al. (2016), pois a partir da primeira análise dos constructos propostos, pode-se verificar a existência de variáveis com valores abaixo de 0,50 para as Variâncias Médias Extraídas (Average Variance Extracted - AVEs) e para as Cargas Externas (CE).

A utilização desses parâmetros ocasionou na retirada de 5 variáveis das 28 propostas inicialmente, possibilitando assim um adequado ajuste no modelo. Pedhazur (1997) ressalta que a exclusão de variáveis se apresenta como um processo comum nas pesquisas de SEM, no qual o objetivo final é encontrar um grupo de variáveis aderentes a um modelo que possua capacidade de explicá-lo de modo mais abrangente possível.

As variáveis excluídas foram Controle da Corrupção do constructo Estabilidade Política; Execução de Contratos e Custos no Comércio Internacional do constructo Custos na Prestação de Serviços; e Inflação e Taxa de Desemprego do constructo Fatores Econômicos.

Para definição dos sinais esperados nas hipóteses do Quadro 1, foram escolhidos sinais positivos ou negativos que mais condizem com a literatura em questão. E para uma primeira análise e interpretação do modelo gerado, a Tabela 1 apresenta a matriz de validade discriminante que ampara na interpretação dos constructos. A diagonal principal é composta pelas raízes quadradas do AVE e fora dela estão as correlações.

Tabela 1 - Validade Discriminante e estatística descritiva do modelo.

\begin{tabular}{llcccccc}
\hline \multicolumn{1}{c}{ Variável latente } & $(1)$ & $(2)$ & $(3)$ & $(4)$ & (5) & (6) \\
\hline (1) & Estabilidade Política & $\mathbf{0 , 9 3 9}$ & & & & & \\
$(2)$ & Custos na Prestação de Serviços & $-0,565$ & $\mathbf{0 , 7 2 3}$ & & & & \\
(3) & Regulações Políticas & 0,828 & $-0,490$ & $\mathbf{0 , 9 7 9}$ & & & \\
(4) & Desempenho na Prestação de Serviços & 0,787 & $-0,465$ & 0,943 & $\mathbf{0 , 9 5 3}$ & & \\
(5) & Fatores Econômicos & 0,228 & $-0,137$ & 0,361 & 0,331 & $\mathbf{0 , 9 7 6}$ & \\
$(6)$ & Fatores Socioculturais & 0,853 & $-0,571$ & 0,789 & 0,775 & 0,242 & $\mathbf{0 , 9 3 2}$ \\
\hline
\end{tabular}

Nota: Nas diagonais são as raízes quadradas do AVE (Variância Média Extraída) e fora das diagonais são as correlações entre os constructos.

Fonte: dados da pesquisa.

No que se refere a avaliação da colinearidade entre os constructos, Hair et al. (2016) argumentam que os valores aceitáveis para os fatores de inflação de variância (Variance Inflation Factor - VIF) devem ser inferiores a 5 .

Devido os indicadores de desempenho logístico terem sido retirados de um único banco de dados (LPI), os constructos Regulações Políticas e Desempenho na Prestação de Serviços se apresentaram correlacionados e identificou-se o problema de multicolinearidade. Foram feitos testes com o modelo retirando um desses constructos de cada vez e constatou-se que os valores eram similares para os demais testes, quando se comparado com o modelo completo, alterando apenas os valores VIF. 
Desta forma, os dados foram analisados separadamente e em um único modelo, mas por fim didático os mesmos serão apresentados apenas em um único modelo. Os VIF internos, que se referem aos constructos em questão e analisados separados, mantiveram-se todos inferiores a 1,48 e satisfazendo o pressuposto da literatura.

Um bom ajuste do modelo de mensuração estrutural requer que alguns parâmetros sejam atendidos, sendo os mais convencionais para se validar constructos reflexivos em modelos PLS-SEM a Validade Convergente, Confiabilidade da Consistência Interna e Validade Discriminante (CHIN, 1998; GÖTZ; LIEHR-GOBBERS; KRAFFT, 2010; HAIR et al., 2016). A Tabela 2 apresenta os resultados desses parâmetros para um melhor ajuste do modelo em estudo.

Tabela 2 - Síntese dos resultados do modelo de medição reflexiva.

\begin{tabular}{|c|c|c|c|c|c|c|}
\hline \multirow{3}{*}{ Variável latente } & \multirow{3}{*}{ Indicador } & \multicolumn{2}{|c|}{ Validade Convergente } & \multicolumn{2}{|c|}{$\begin{array}{c}\text { Confiabilidade da } \\
\text { Consistência Interna } \\
\end{array}$} & \multirow{2}{*}{$\begin{array}{c}\begin{array}{c}\text { Validade } \\
\text { Discriminante }\end{array} \\
\text { Fornell-Larcker }\end{array}$} \\
\hline & & $\begin{array}{l}\text { Cargas } \\
\text { Externas }\end{array}$ & $\begin{array}{l}\text { Variância Média } \\
\text { Extraída }\end{array}$ & $\begin{array}{l}\text { Alfa de } \\
\text { Cronbach }\end{array}$ & $\begin{array}{l}\text { Confiabilidade } \\
\text { Composta }\end{array}$ & \\
\hline & & $\mathrm{CE}>0,50$ & AVE $>0,50$ & $\mathrm{AC}>0,70$ & $\mathrm{CC}>0,70$ & Critério $=\sqrt{\mathrm{AVE}}$ \\
\hline \multirow{4}{*}{$\begin{array}{l}\text { Estabilidade } \\
\text { Política }\end{array}$} & EfG & 0,975 & \multirow{4}{*}{0,881} & \multirow{4}{*}{0,954} & \multirow{4}{*}{0,967} & \multirow{4}{*}{0,939} \\
\hline & EqP & 0,824 & & & & \\
\hline & IED & 0,982 & & & & \\
\hline & QuR & 0,964 & & & & \\
\hline \multirow{4}{*}{$\begin{array}{l}\text { Custos na } \\
\text { Prestação de } \\
\text { Serviços }\end{array}$} & CIN & 0,736 & \multirow{4}{*}{0,522} & \multirow{4}{*}{0,751} & \multirow{4}{*}{0,814} & \multirow{4}{*}{0,723} \\
\hline & PgI & 0,682 & & & & \\
\hline & NIP & 0,757 & & & & \\
\hline & TxI & 0,691 & & & & \\
\hline \multirow{3}{*}{$\begin{array}{l}\text { Regulações } \\
\text { Políticas }\end{array}$} & Alf & 0,976 & \multirow{3}{*}{0,958} & \multirow{3}{*}{0,978} & \multirow{3}{*}{0,986} & \multirow{3}{*}{0,979} \\
\hline & Inf & 0,983 & & & & \\
\hline & QCL & 0,977 & & & & \\
\hline \multirow{3}{*}{$\begin{array}{l}\text { Desempenho na } \\
\text { Prestação de } \\
\text { Serviços }\end{array}$} & Pre & 0,952 & \multirow{3}{*}{0,908} & \multirow{3}{*}{0,950} & \multirow{3}{*}{0,967} & \multirow{3}{*}{0,953} \\
\hline & $\mathrm{CaI}$ & 0,943 & & & & \\
\hline & MoR & 0,964 & & & & \\
\hline \multirow{4}{*}{$\begin{array}{l}\text { Fatores } \\
\text { Econômicos }\end{array}$} & PIB & 0,999 & \multirow{4}{*}{0,953} & \multirow{4}{*}{0,983} & \multirow{4}{*}{0,988} & \multirow{4}{*}{0,976} \\
\hline & ICF & 0,935 & & & & \\
\hline & VAS & 0,987 & & & & \\
\hline & $\mathrm{CoF}$ & 0,982 & & & & \\
\hline \multirow{5}{*}{$\begin{array}{c}\text { Fatores } \\
\text { Socioculturais }\end{array}$} & $\mathrm{IDH}$ & 0,967 & \multirow{5}{*}{0,869} & \multirow{5}{*}{0,962} & & \\
\hline & InG & 0,947 & & & & \\
\hline & PMA & 0,860 & & & 0,971 & 0,932 \\
\hline & GIS & 0,969 & & & & \\
\hline & $\mathrm{ExV}$ & 0,914 & & & & \\
\hline
\end{tabular}

Nota: EfG (Efetividade do Governo); EqP (Equilíbrio Político); IED (Índice do Estado de Direito); QuR (Qualidade Regulatória); CIN (Custo de Iniciar um negócio); PgI (Pagamento de Imposto); NIP (Número de impostos pagos pelas empresas); TxI (Taxa de imposto, percentagem de lucros comerciais); Alf (Alfândega); Inf (Infraestrutura); QCL (Qualidade e Comp. Logística); Pre (Previsibilidade); CaI (Carregamentos Internacionais); MoR (Monitoramento e Rastreabilidade); PIB (Produto Interno Bruto); ICF (Investimento em Capital Fixo); VAS (Valor Adicionado de Serviço); CoF (Consumo das Famílias); IDH (Índice de Desenvolvimento Humano); InG (Índice de Globalização); PMA (População maior que 65 anos); GIS (Globalização Social); ExV (Expectativa de Vida).

Fonte: Dados da pesquisa.

A validade convergente, segundo Nascimento e Macedo (2016), é a extensão em que uma medida se correlaciona de forma positiva com outras medidas do mesmo constructo. Em primeiro plano ressalta- 
se a confiabilidade dos indicadores, sendo confirmada pelo alto valor das cargas externas no mesmo constructo, o que demonstra que os indicadores em questão possuem afinidades com o fenômeno captado pelo constructo.

Hair et al. (2016) e Guedes Neto et al. (2016) afirmam que quando o peso externo do indicador não é significativo, contudo, a sua carga externa é superior a 0,50, o indicador é relativamente importante e deve ser mantido. Para o modelo em análise, todas as cargas externas foram superiores a 0,50 , atendendo assim esse pressuposto.

Fornell e Larcker (1981) apresentam que quando a AVE é superior a 0,50, assume-se que o modelo converge a um resultado satisfatório. Nesse vértice, todos os constructos apresentaram-se satisfatórios com AVE superior a 0,50, sendo o menor deles igual a 0,522 referente ao constructo Custos na Prestação de Serviços.

$\mathrm{Na}$ Confiabilidade da Consistência Interna, que remete a confiabilidade do modelo, dois pontos são relevantes: o Alfa de Cronbach, no qual assume que todos os indicadores são igualmente confiáveis, e a Confiabilidade Composta, que leva em consideração diferentes cargas externas das variáveis indicadoras e sendo utilizada para avaliar se a amostra está livre de vieses e são confiáveis (HAIR et al., 2016).

Tanto para a Confiabilidade Composta quanto para o Alfa de Cronbach os valores devem estar acima de 0,70 (AC > 0,70; CC > 0,70), o que assegura um melhor ajuste do modelo (HAIR et al., 2016). No modelo em questão ambos critérios foram atendidos para todos os constructos.

O modelo proposto também atendeu ao princípio da validade discriminante, como pode ser visto na Tabela 2. Para Hair et al. (2016) a validade discriminante verifica a medida em que um constructo é genuinamente distinto dos demais constructos em um modelo estrutural e capta fenômenos não compreendidos nos demais. O critério proposto por Fornell e Larcker (1981), um dos mais conservadores em se avaliar a validade discriminante, é mensurado por meio da confrontação das raízes quadradas das variâncias médias extraídas diante das correlações de Pearson entre os demais constructos latentes.

Os valores confrontados devem ser iguais para se possuir validade discriminante no modelo. Conforme visualizado na Tabela 2, os valores de Pearson são idênticos aos valores das raízes quadradas da AVE (ver diagonal principal da Tabela 1).

\section{Análise do Modelo Estrutural e teste das hipóteses}

Neste momento, direciona-se a análise para o modelo estrutural e testar se as hipóteses delineadas na pesquisa foram satisfeitas. A Figura 3 apresenta os coeficientes de determinação (R2) representados no interior dos círculos em azuis, e os t-values (betas) das cargas externas (valores entre as linhas).

Quanto aos valores de R2, trabalhos como os de Chin (1998), Henseler, Ringle e Sinkovics (2009) e Hair et al. (2016) mostram que valores de 0,67,0,33 e 0,19 para os constructos endógenos do modelo interno são considerados como substanciais, moderados ou fracos, respectivamente. Contudo, trabalhos da área de ciências, tais como Cohen (1988) e Bido e Silva (2019), consideram efeitos para R2 equivalentes a pequeno, médio e grande, com valores referentes a 0,02, 0,13 e 0,26 , respectivamente. 
Figura 3 - Modelo Estrutural e suas determinantes.

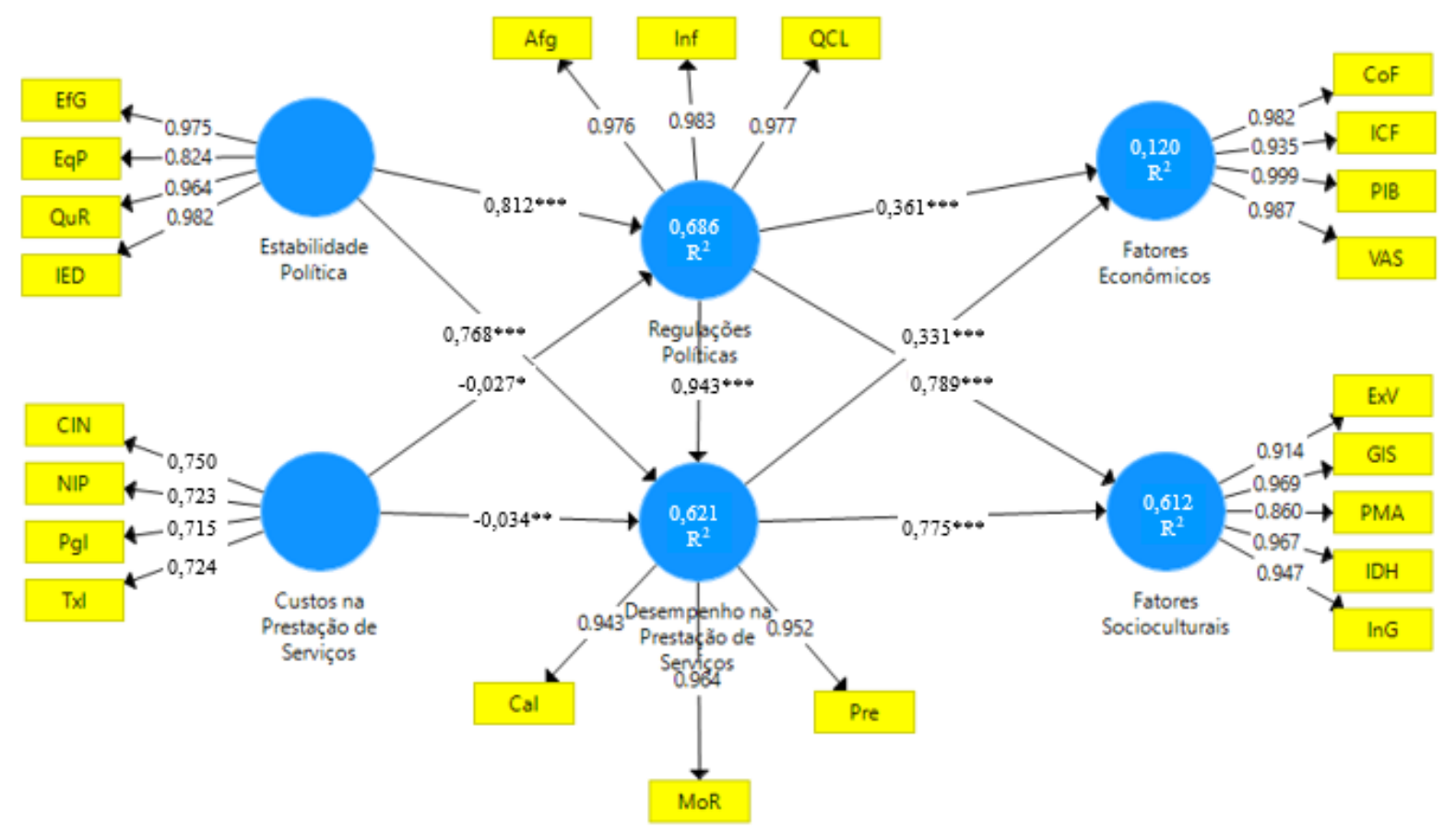

Nota: *, **,*** Estatisticamente significante ao nível de 0,1;0,05 e 0,001 respectivamente.

Fonte: Saída do software SmartPLS.

As Regulações Políticas como variável explicativa no modelo gerado apresentaram um R2 de 0,686. Isto significa que 68,6\% das variações ocorridas no constructo Regulações Políticas podem ser atribuídas as suas determinantes de Estabilidade Política e Custos na Prestação de Serviços. Um percentual considerável se comparado aos valores de referência.

Outra variável endógena que também apresentou um alto valor de R2 (0,621) foi o Desempenho na Prestação de Serviços, no qual constata-se que 62,1\% desse desempenho é explicado pelas variáveis latentes Estabilidade Política, Custos na Prestação de Serviços e Regulações Políticas.

No que tange o grau de explicação das variáveis endógenas alvo, Fatores Econômicos e Fatores Socioculturais, a primeira dessas apresentou um efeito fraco de R2 $(0,120)$. Não se esperava nesta relação um alto valor, visto que diversos outros fatores impactam mais diretamente nas questões econômicas do que os fatores de desempenho logístico, representados pelas Regulações Políticas e pelos Custos na Prestação de Serviços.

Com um resultado mais expressivo, os Fatores Socioculturais apresentaram um alto valor R2, igual a 0,612, indicando que $61,2 \%$ das questões socioculturais podem serem influenciadas pelas Regulações Políticas e pelo Desempenho na Prestação de Serviços.

Para aferir a validade preditiva referente a cada constructo endógeno, foi observado os coeficientes Q2 de Stone-Geisser, obtido por meio do método não paramétrico blindfolding, que segundo Hair et al. (2016) tem a especificação de um modelo de mensuração reflexiva ou de item único, no qual valores acima de 0 indicam que o modelo apresenta relevância preditiva.

Os constructos Regulações Políticas, Desempenho na Prestação de Serviços, Fatores Econômicos e Fatores Socioculturais apresentaram valores de Q2 iguais a 0,620;0,764;0,116;0,505 respectivamente, podendo-se concluir que todos esses constructos exógenos possuem grande relevância preditiva sobre os constructos endógenos, com maior relevância preditiva para o Desempenho na Prestação de Serviços $(\mathrm{Q} 2=0,764)$. 
Segundo Henseler, Ringle e Sinkovics (2009) e Hair et al. (2016), as estimativas para coeficientes de caminho do modelo estrutural representam valores estimados das relações de trajetória no modelo e devem ser analisados nos quesitos sinal, magnitude e significância pelo procedimento bootstrapping.

Desta forma, para análise do modelo estrutural, foi realizado um procedimento de bootstrapping completo com um total de 5.000 subamostras, onde observa-se os coeficientes e as hipóteses da pesquisa. Este procedimento visa garantir a robustez do modelo de caminhos e possibilita verificar os coeficientes e as hipóteses propostas na pesquisa.

Nessa perspectiva, a Tabela 3 apresenta os resultados das hipóteses de pesquisa. O resultado mostra que das relações testadas todos os constructos tiveram um $\beta$ significativo. Segundo Hair et al. (2016), o parâmetro para se aceitar alguma hipótese teórica no modelo estrutural por meio da estatística T é que o valor seja maior que 1,96 (5\% de significância). Isto acontece para todas as relações/hipóteses testadas com exceção da Hipótese 3, embora ela seja significativa a 10\%.

Tabela 3 - Hipóteses da pesquisa e seus resultados.

\begin{tabular}{|c|c|c|c|c|c|c|}
\hline \multirow[t]{2}{*}{ Relações Estruturais } & $\begin{array}{l}\text { Coeficiente } \\
\text { de caminho }\end{array}$ & $\begin{array}{c}\text { Valor de } \\
\text { T } \\
\end{array}$ & $\begin{array}{l}\text { Tamanho } \\
\text { do Efeito }\end{array}$ & \multirow{2}{*}{$\begin{array}{l}\text { Hipótese } \\
\text { e Sinal } \\
\text { Esperado }\end{array}$} & \multirow{2}{*}{$\begin{array}{c}\text { Sinal } \\
\text { Encontrado }\end{array}$} & \multirow[t]{2}{*}{ Resultado } \\
\hline & $(\beta)$ & $\mathrm{T}>1,96$ & $f^{2}$ & & & \\
\hline Estabilidade Política -> RP & $0,812^{* * *}$ & 74,166 & 1,419 & $\mathrm{H} 1(+)$ & + & Aceita \\
\hline Estabilidade Política -> DPS & $0,768^{* * *}$ & 66,453 & 1,067 & $\mathrm{H} 2(+)$ & + & Aceita \\
\hline Custos na Prestação de Serviços -> RP & $-0,027 *$ & 1,864 & 0,002 & H3 (-) & - & Aceita \\
\hline Custos na Prestação de Serviços -> DPS & $-0,034 * *$ & 2,315 & 0,002 & $\mathrm{H} 4(-)$ & - & Aceita \\
\hline Regulações Políticas -> FE & $0,361 * * *$ & 29,272 & 0,150 & $\mathrm{H} 5(+)$ & + & Aceita \\
\hline Regulações Políticas -> FS & $0,789 * * *$ & 110,805 & 1,651 & H6 (+) & + & Aceita \\
\hline Desempenho na Prestação de Serviços -> FE & $0,331 * * *$ & 28,660 & 0,123 & $\mathrm{H} 7(+)$ & + & Aceita \\
\hline Desempenho na Prestação de Serviços -> FS & $0,775^{* * *}$ & 97,225 & 1,504 & $\mathrm{H} 8(+)$ & + & Aceita \\
\hline Regulações Políticas -> DPS & $0,943 * * *$ & 407,888 & 8,105 & $\mathrm{H} 9(+)$ & + & Aceita \\
\hline
\end{tabular}

Nota: *** Estatisticamente significante ao nível de 0,001. *** $\mathrm{p}<0,01,{ }^{* *} \mathrm{p}<0,05,{ }^{*} \mathrm{p}<0,10$. RP (Regulações Políticas); DPS (Desempenho na Prestação de Serviços); FE (Fatores Econômicos); FS (Fatores Socioculturais). Para o Tamanho de efeito $\mathrm{f}^{2}$ valores 0,02 (efeitos pequenos), 0,15 (efeitos médios) e 0,35 (efeitos grandes).

Fonte: dados da pesquisa.

A Tabela 3 apesenta também os resultados do tamanho do efeito $\mathrm{f}^{2}$ nas relações estruturais do modelo. O indicador f2 sinaliza o valor absoluto da contribuição individual. Henseler, Ringle e Sinkovics (2009) e Hair et al. (2016) relatam que f2 com valores de 0,02, 0,15 e 0,35, indicam respectivamente, efeitos pequenos, efeitos médios e efeitos grandes dos constructos exógenos.

Por meio das análises do modelo podemos constatar que o constructo Custos na Prestação de Serviços apresentou um efeito pequeno sobre as Regulações Políticas e sobre o Desempenho na Prestação de Serviços, com valores f2 iguais a 0,002 para ambos os efeitos. As Regulações Políticas e o Desempenho na Prestação de Serviços, quando relacionados com os Fatores Econômicos, apresentaram uma relação com efeito médio para f2 igual a 0,150 e 0,123, respectivamente. As demais relações apresentaram um efeito grande nas relações estruturais do modelo, com maior efeito para o f2 de 8,105 correspondente ao impacto das Regulações Políticas sobre o Desempenho na Prestação de Serviços.

Hair et al., (2016) afirmam que a utilização de muitos indicadores aumenta a probabilidade de ser adquiridos pesos externos baixos ou até mesmo não significantes. Nesse aspecto, torna-se proeminente considerar a contribuição absoluta do indicador formativo para o constructo, ou seja, a informação que $\mathrm{o}$ indicador fornece sem considerar nenhum outro indicador. 
Em vista dos resultados obtidos, pode-se concluir que a Estabilidade Política dos países impacta positivamente sobre as Regulações Políticas $(\beta=0,812 ; \mathrm{p}<0,001)$ e sobre o Desempenho na Prestação de Serviços $(\beta=0,768 ; p<0,001)$, o que confirma as Hipóteses 1 e 2 . Esse fato comprova que um país estável politicamente e com um baixo índice de corrupção pode impactar positivamente no seu desempenho logístico e nas relações comerciais com outros países, fornecendo um ambiente mais estável e previsível para as negociações.

Nesse vértice, por meio da análise dos coeficientes de caminho da Figura 3, constatamos que a Estabilidade Política apresenta um efeito mais forte sobre as Regulações Políticas $(\beta=0,812)$, indicando que um país estável politicamente apresenta melhores regulações políticas ligadas ao sistema logístico. Kobayashi, (2000) apresenta que a organização político-social é um fator fundamental para se alcançar a eficiência da estrutura de um sistema logístico.

Os Custos na Prestação de Serviços associam-se negativamente com a Estabilidade Política $(\beta=-0,027$; $\mathrm{p}<0,1)$ e com o Desempenho na Prestação de Serviços $(\beta=-0,034 ; p<0,05)$ sustentando as Hipótese 3 e 4. Deste modo, nota-se que os Custos na Prestação de Serviços interferem mais negativamente $(\beta=$ 0,034) sobre o Desempenho na Prestação de Serviços, o que demonstra que os custos presentes nas relações de prestação de serviços são mais significativos no desempenho das prestadoras de serviços do que nas regulações políticas (fatores institucionais).

A estrutura de governança que a empresa adota e a forma como ela se posiciona no mercado, reflete diretamente nesses custos de transacionar com o mercado, segundo a TCT. Os resultados mostram que o desempenho logístico é influenciado pelos custos e comprovam mais uma vez, a importância de considerar indicadores relativos aos custos, quando está em análise a estrutura logística dos países (KOBAYASHI, 2000; REY, 1999). São também similares aos trabalhos de Limão e Venables (2001), Kobayashi (2000) e Bougheas Demetriades e Morgenroth (1999), no qual sinalizam o impacto direto dos custos no sistema logístico, em suas estratégias e volume de comércio.

As Hipóteses 5 e 6, referentes ao impacto das Regulações Políticas sobre os Fatores Econômicos $(\beta=0,361 ; \mathrm{p}<0,001)$ e Fatores Socioculturais $(\beta=0,789 ; \mathrm{p}<0,001)$, respectivamente, relacionam se positivamente, demonstrando a grande interferência das ações políticas ligadas ao setor logístico sobre o desenvolvimento econômico e questões socioculturais dos países, corroborando com o trabalho de Williamson (2000) que apresenta o ambiente institucional como um influenciador nas estruturas de governanças e, continuamente, na designação de recursos econômicos.

Foi notada ainda uma relação significante entre o Desempenho na Prestação de Serviços e os Fatores Econômicos $(\beta=0,331 ; \mathrm{p}<0,001)$, permitindo, assim, confirmar a Hipótese $\mathrm{H} 7$ e constatar o efeito que as prestadoras de serviços logístico causam sobre as questões econômicas do país. Esse resultado, em conjunto com a constatação da Hipótese 5, confirma os achados de Martí, Puertas e Gárcia (2014) que ressaltam a importância do desempenho logístico para o fluxo de comércio e consequentemente para o crescimento econômico dos países.

Ballou (2003) e Carlsson, Otto e Hall (2013) ressaltam que a falta de um sistema logístico adequado deixa os países estagnados em um padrão de vida relativamente baixo e sem previsão de melhorias e os investimentos em infraestrutura são fundamentais para o crescimento econômico de qualquer nação. Assim como Cabral e Silva Júnior (2011) defendem que a falta de investimento em infraestrutura logística compromete o crescimento econômico do Brasil.

Além desse ponto, o Desempenho na Prestação de Serviços também impacta positivamente os Fatores Socioculturais $(\beta=0,775 ; p<0,001)$, conforme constatado na Hipótese 8. Sem uma relação positiva entre eficiência logística e progresso, o padrão de vida se estagna em uma situação de subdesenvolvimento (BALLOU, 2006). 
Por último, encontrou-se uma relação positiva e significante a 1\% entre as Regulações Políticas e o Desempenho na Prestação de Serviços $(\beta=0,943)$, confirmando a Hipótese 9. Esse fato indica que ações políticas eficazes irão gerar melhores resultados no desempenho logísticos, assim como assinalado pelo Banco Mundial (2018) em seu esquema teórico do LPI. Boehe e Zawislak (2007) afirmam que fatores institucionais podem influenciar melhores práticas organizacionais por meio de regras governamentais.

Essa relação também mostra a complexidade das empresas logísticas em obterem bons resultados, uma vez que seu ambiente econômico é impactado diretamente por questões políticas, o que gera a necessidade de se criar adaptações e correções contratuais devido essas incertezas do ambiente. Além disso, conforme afirma Williamson (2007), essas incertezas podem provocar falhas de mercado e custos de transação que são exploradas de maneira oportunista.

A Figura 4 sintetiza as hipóteses testadas de modo a facilitar a compreensão do resultado.

Figura 4 - Síntese dos resultados da pesquisa.

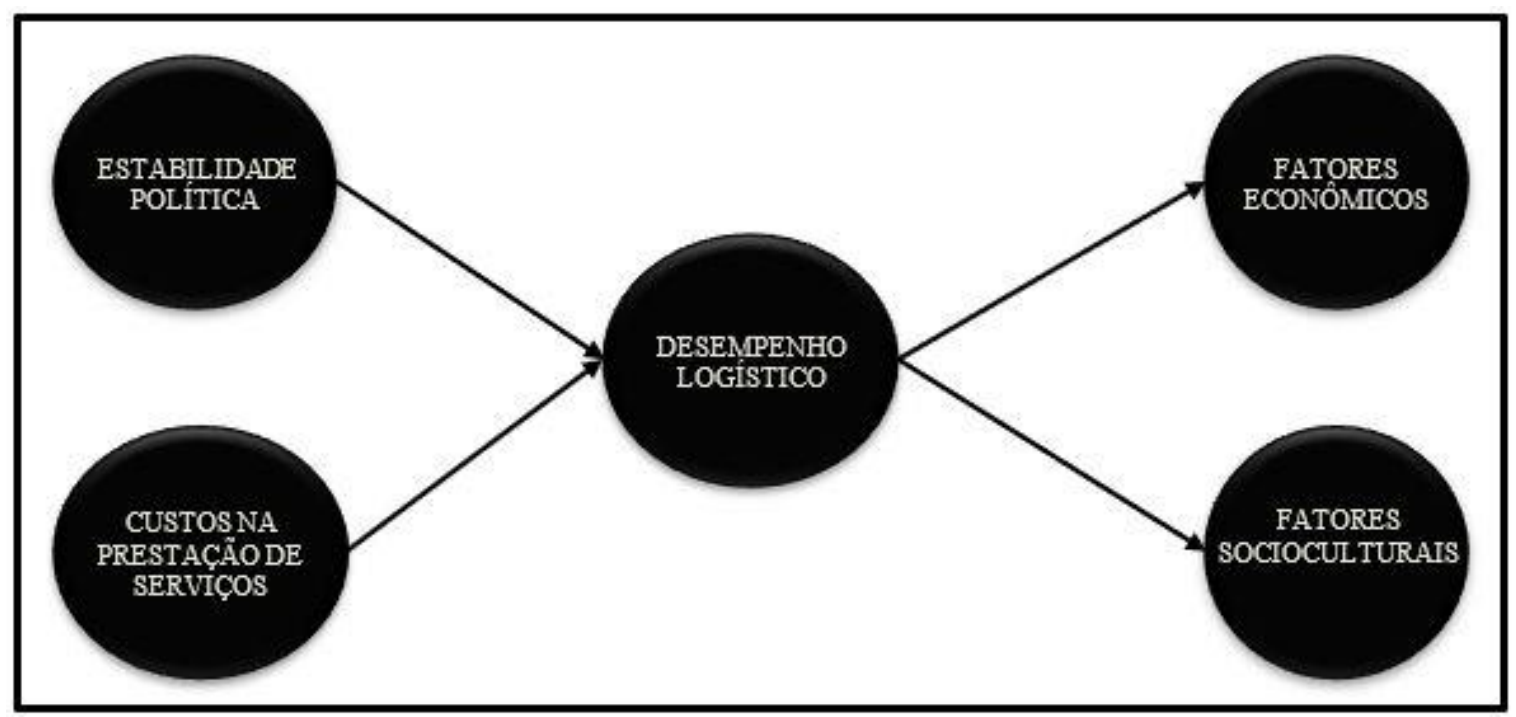

Fonte: Resultado da Pesquisa.

Kock (2015) ressalta que as relações entre constructos latentes são não lineares, ou seja, não há uma tendência linear global, tendo em vista que o coeficiente de caminho é côncavo em algum ponto da relação. Como exemplo disso, não podemos dizer que um crescimento exponencial do Desempenho Logístico causará, consecutivamente, o aumento dos Fatores Econômicos em questão.

Por fim, cabe ressaltar o suporte teórico da NEI com a pesquisa em questão. Os fatores institucionais e as características das transações, que representam o desempenho logístico (indicadores LPI), se relacionam diretamente com os custos de transação, onde contribui na identificação da melhor forma de estabelecer transações econômicas com os países e empresas, além de explicar a interação entre ambiente institucional e mercado.

\section{Conclusão}

A presente pesquisa teve como objetivo verificar como a estabilidade política e os custos na prestação de serviços causam impacto sobre o desempenho logístico e se estes interferem nos fatores econômicos e socioculturais dos países. Nesse aspecto, a modelagem de equações estruturais visa contribuir com novas perspectivas de análise, além de apresentar resultados robustos e confiáveis.

Os resultados desse trabalho indicam que a estabilidade política e os custos na prestação de serviços interferem diretamente no desempenho logístico dos países, tanto em suas regulações políticas de cunho 
institucional, como na prestação de serviço das empresas privadas. É imprescindível analisar a situação política do país e os custos de se relacionar com ele, além de mensurar o impacto de sua estrutura logística nas transações comerciais.

O melhor desempenho logístico gera diretamente um maior volume de produtos comercializados e menores custos de transporte (BOUGHEAS; DEMETRIADES; MORGENROTH, 1999). A infraestrutura do sistema logístico impacta em toda cadeia produtiva de um país, principalmente nos custos, desempenho e fluxo comercial (SOLIANI, 2018). O ambiente dinâmico e cheio de desafios, no qual as organizações estão inseridas, fazem com que as ações sejam planejadas de modo antecipado, articulando as estratégias e analisando sistematicamente o cenário externo e toda sua estrutura, assim como se analisa as condições internas.

Os custos de transação, objetivo fundamental da NEI, mostrou-se adequado às analises em estudo, onde a utilização de indicadores ligados a custos na prestação de serviços são cada vez mais relevantes na análise do desempenho logístico. Segundo a teoria, a frequência das transações pode gerar maior confiabilidade nesses processos, além de reduzir os riscos das incertezas com o auxílio de melhores cláusulas contratuais e gerar economia de escala e escopo nas transações.

Os fatores institucionais, representados pelo constructo das Regulações Políticas, impactam diretamente nos fatores econômicos e socioculturais dos países, além de interferir diretamente no desempenho das prestadoras de serviços logísticos. Esses resultados corroboram com os princípios da NEI expostos por Williamson (1975, 1985, 1989, 1991 e 1993), no qual defende que os custos de transacionar com o mercado ocorre em um ambiente institucional que interfere diretamente nas relações contratuais.

Embora o conhecimento humano seja baseado em uma racionalidade limitada e o ambiente institucional esteja repleto de incertezas, conforme apresentado na NEI, o desenvolvimento de modelos como o que este trabalho propõe são fundamentais para se conhecer melhor o sistema logístico e seu impacto nas questões econômicas e sociais dos países, além de criar bases de comparação para as empresas que estão sempre na busca de vantagens competitivas a partir desse sistema.

O modelo proposto também possibilitou constatar que o bom desempenho das prestadoras de serviços logísticos contribui para uma melhora dos fatores econômicos e socioculturais. Essas relações positivas e significativas demonstram, mais uma vez, a importância que o sistema logístico bem estruturado tem no desenvolvimento dos países, independentemente de suas dimensões territoriais e localização geográfica.

Conforme apresentaram Carlsson, Otto e Hall (2013) e constatado nessa pesquisa, a infraestrutura logística impacta diretamente o crescimento econômico dos países. $\mathrm{O}$ ambiente organizacional influencia e é influenciado constantemente por questões políticas, econômicas e sociais. A confiabilidade do setor logístico gera um ambiente mais seguro para traçar estratégias de crescimento econômico e criar políticas públicas segundo as demandas sociais do país e as particularidades de cada região.

Os resultados contribuem para o mercado no sentido de apresentar o impacto que a estabilidade política e os custos têm no desempenho logístico dos países, sendo um fator de análise dos gestores antes de negociarem no mercado internacional. E como contribuição acadêmica, expande o conhecimento e a discussão teórica sobre o desempenho logístico através da perspectiva da Nova Economia Institucional, no qual aponta caminhos por meio de uma análise empírica para novas pesquisas no campo em questão.

Um sistema que proporciona eficiência nas operações logísticas, principalmente no mercado internacional, se concretiza como responsável pela construção do apoio indispensável para a execução de um comércio promissor e significativo (BALLOU, 2006). A falta de uma ligação entre eficiência no sistema logístico e progresso, gera uma estagnação no padrão de vida e acarreta uma situação de subdesenvolvimento do país. 
Como limitação deste trabalho, destaca-se a impossibilidade de as variáveis utilizadas representar a amplitude total dos constructos, sabendo que há outras variáveis que influenciam os custos e a estabilidade política dos países, assim como seus fatores econômicos e socioculturais, que não foram considerados neste modelo. Cita-se também o pequeno número das pesquisas LPI (seis edições), no qual um maior horizonte de tempo traria mais robustez ao modelo.

Posto isso, para trabalhos futuros sugere-se que sejam realizadas pesquisas mais longitudinais e direcionadas a novos constructos e variáveis que possam melhor expressar esses fatores em análise, abrangendo novas metodologias e bases teóricas que permitirão o aprimoramento da ciência e o desenvolvimento dos países.

\section{Referências}

ARBAGE, A. P. (2004). Custos de transação e seu impacto na formação e gestão da cadeia de suprimentos: estudo de caso em estruturas de governança bibridas do sistema agroalimentar no Rio Grande do Sul. Tese (Doutorado em Administração) - Universidade Federal do Rio Grande do Sul, Porto Alegre, RS, Brasil.

ARGYRES, N., MAHONEY, J. T., \& NICKERSON, J. (2019). Strategic responses to shocks: Comparative adjustment costs, transaction costs, and opportunity costs. Strategic Management Journal, 40(3), pp. 357-376.

ARVIS, J. F., MUSTRA, M. A., OJALA, L., SHEPHERD, B., \& SASLAVSKY, D. (2014). Connecting to Compete 2014: Trade Logistics in the Global Economy. Washington, DC: World Bank.

BALLOU, R. H. (2006). Gerenciamento da cadeia de suprimentos: Logística Empresarial (5a ed). Porto Alegre: Bookman.

BALLOU, R. H. (2003). Logística empresarial. São Paulo: Atlas.

BANCO MUNDIAL. (2019). Connecting to compete 2016: trade logistics in the global economy. Disponível em: $<$ https://lpi.worldbank.org/>. Acesso em: 21 jan. 2019.

BANCO MUNDIAL. (2019). Connecting to compete 2018: trade logistics in the global economy. Disponível em: $<$ https://lpi.worldbank.org/>. Acesso em: 21 jan. 2019.

BAZANI, C. L. (2017). Desempenho logístico do Brasil no mercado internacional: análise do indice LPI. 2017.

Dissertação (Mestrado em Ciências Contábeis) - Universidade Federal de Uberlândia, Uberlândia, MG, Brasil.

BIDO, D. S., \& SILVA, D. (2019). SmartPLS 3: especificação, estimação, avaliação e relato. Administração: Ensino e Pesquisa, 20(2), pp. 1-31.

BOEHE, D. M., \& ZAWISLAK, P. A. (2007). Influências ambientais e inovação de produtos: estudo de casos em subsidiárias de multinacionais no Brasil. Revista de Administração Contemporânea, 11(1), pp. 97-117.

BOUGHEAS, S., DEMETRIADES, P., \& MORGENROTH, E. (1999). Infrastructure, transport costs and trade. Journal of International Economics, 47(1), pp. 169-189.

CABRAL, S., \& SILVA JÚNIOR, A. F. (2011). Escolhas estratégicas para expansão de uma malha ferroviária: uma análise baseada em opções reais. Revista Base (Administração e Contabilidade) da UNISINOS, 8(1), pp. 78-90.

CARLSSON, R., OTTO, A., \& HALL, J. W. (2013). The role of infrastructure in macroeconomic growth theories. Civil Engineering and Environmental Systems, 30(3-4), pp. 263-273.

CHIN, W. W. (1998). The partial least squares approach to structural equation modeling. Modern Methods for Business Research, 295(2), pp. 295-336.

COASE, R. H. (1937). The nature of the firm. Economica New Series, 4(16), pp. 386-405.

COASE, R. H. (1960). The Problem of Social Cost. Journal of Law and Economics, 3, pp. 1-44. 
COHEN, J. (1988). Statistical Power Analysis for the Behavioral Sciences (2a ed.). New York: Psychology Press.

CSCMP - COUNCIL OF SUPPLY CHAIN MANAGEMENT PROFESSIONALS. (2018). Supply chain and logistics terms and glossary. Disponível em: <https://cscmp.org/supply-chain-managementdefinitions> Acesso em: 08 dez. 2018.

CUNHA, C. F., SAES, M. S. M., \& MAINVILEE, D. Y. (2015). Custo de transação e mensuração na escolha da estrutura de governança entre supermercados e produtores agrícolas convencionais e orgânicos no Brasil e nos EUA. Gestão e Produção, 22(1), pp. 67-81.

DAGDEVIREN, H., \& ROBERTSON, S. A. (2013). A critical assessment of the incomplete contracts theory for private participation in public services: the case of the water sector in Ghana. Cambridge Journal of Economics, 37(5), pp. 1057-1075.

FARIA, R. N. de, SOUZA, C. S. de, \& VIEIRA, J. G. V. (2015). Evaluation of logistic performance indexes of Brazil in the international trade. RAM. Revista de Administração Mackenzie, 16(1), pp. 213-235. FATTIBENE, M., MOURA, A. B., CASSETARI, A., VIEIRA, J. G. V., \& SILVA, J. E. A. R. (2012). Desempenho logístico do Brasil no comércio internacional: estudo dos indicadores alfândega e pontualidade. Anais do Encontro Nacional de Engenharia de Produção, Bento Gonçalves, RS, Brasil, 32. FORNELL, C., \& LARCKER, D.F. (1981). Evaluating structural equation models with unobservable variables and measurement error. Journal of Marketing Research, 18(1), pp. 39-50.

FRAINER, D. M. A estrutura e a dinâmica da indústria automobilística no Brasil. (2010). Tese (Doutorado em Economia) - Universidade Federal do Rio Grande do Sul, Porto Alegre, RS, Brasil.

GARAFFA, R., SZKLO, A., LUCENA, A. F., \& FÉRES, J. G. (2019). Price Adjustments and Transaction Costs in the European Natural Gas Market. Energy Journal, 40(1).

GOMES, C. F. S., \& RIBEIRO, P. C. C. (2004). Gestão da cadeia de suprimentos integrada à tecnologia da informação. São Paulo: Pioneira Thomson Learning.

GÖTZ, O., LIEHR-GOBBERS, K., \& KRAFFT, M. (2010). Evaluation of structural equation models using the partial least squares (PLS) approach. In: Handbook of partial least squares (pp. 691-711). Springer Berlin Heidelberg.

GUEDES NETO, M., AVRICHIR, I., SILVA, D., \& FIGUEIREDO, C. C. (2016). Adaptação e validação de instrumento de medida de competências interculturais para estudantes universitários Brasileiros. REGE-Revista de Gestão, 23(1), pp. 20-30.

HAIR, J. F., BLACK, W. C., BABIN, B. J., ANDERSON, R. E., \& TATHAM, R. L. (2009). Análise multivariada de dados (6a ed.). Porto Alegre: Bookman.

HAIR, J. F., HULT, G. T. M., RINGLE, C., \& SARSTEDT, M. (2016). A Primer on Partial Least Squares Structural Equation Modeling (PLSSEM) (2a ed.). Los Angeles: SAGE.

HAIR, J. F., RISHER, J. J., SARSTEDT, M., \& RINGLE, C. M. (2019). When to use and how to report the results of PLS-SEM. European Business Review, 31(1), pp. 2-24.

HENSELER, J., RINGLE, C. M., \& SINKOVICS, R. R. (2009). The use of partial least squares path modeling in international marketing. Advances in International Marketing, 20, pp. 277-319.

JOSKOW, P. L. (1995). The new institutional economics: alternative approaches. Journal of Institutional and Theoretical Economics, 151(1), pp. 248-259.

KABAK, Ö., ÜLENGIN, F., \& EKICI, Ş. Ö. (2018). Connecting logistics performance to export: A scenario-based approach. Research in Transportation Economics, 70, pp. 69-82.

KOBAYASHI, S. (2000). Renovação da logística: como definir as estratégias de distribuição física global. São Paulo: Atlas, 2000.

KOCK, N. (2015). WarpPLS 5. 0 user manual. Laredo, TX: ScriptWarp Systems.

LIMÃO, N., \& VENABLES, A. J. (2001). Infrastructure, geographical disadvantage, transport costs and trade. The World Bank Economic Review, 15(3), pp. 451-479. 
MARIANO, E. B., GOBBO JR, J. A., DE CASTRO CAMIOTO, F., \& DO NASCIMENTO REBELATTO, D. A. (2017). CO2 emissions and logistics performance: a composite index proposal. Journal of Cleaner Production, 163, pp. 166-178.

MARTÍ, L., PUERTAS, R., \& GARCÍA, L. (2014). The importance of the Logistics Performance Index in international trade. Applied Economics, 46(24), pp. 2982-2992.

NASCIMENTO, J. C. H. B., \& MACEDO, M. A. S. (2016). Modelagem de equações estruturais com mínimos quadrados parciais: um exemplo da aplicação do SmartPLS® em pesquisas em Contabilidade. Revista de Educação e Pesquisa em Contabilidade, 10(3), pp. 289-313.

PEDHAZUR, E. J. (1997). Multiple regression in behaviorial research: explanation and prediction (3a ed.). Fort Worth: Harcourt Brace.

REY, M. F. (1999). Indicadores de desempenho logístico. Revista Logmam, 30(10), pp. 18-23.

RINGLE, C. M., SILVA, D., \& BIDO, D. S. (2014). Modelagem de equações estruturais com utilização do SmartPLS. Revista Brasileira de Marketing, 13(2), pp. 56-73.

RINGLE, C. M., WENDE, S., \& BECKER, J-M. (2015). SmartPLS 3. Boenningstedt: SmartPLS GmbH, http:/ / wmw. smartpls. com.

ROCHA JUNIOR, W. F., CARVALHEIRO, E. M., STADUTO, J. A., \& OPAZO, M. A. U. (2008). Avaliação de contratos: uma abordagem utilizando a Análise Fatorial de Correspondência. Revista de Economia e Sociologia Rural, 46(2), pp. 455-480.

SOLIANI, R. D. (2018). Evaluation of the Brazilian Logistic Performance in the LPI Index. European International Journal of Science and Technology, 7(8), pp. 35-48.

WATANABE, K. (2007). Relações contratuais no agribusiness. Tese (Doutorado Ciências Aplicadas) Scuola Superiore Sant'Anna di Studi Universitari e Perfezioamento, Pisa, Itália.

WILLIAMSON, O. E. (2007). Transaction cost economics: An introduction. Economics Discussion Paper, 3, pp. 1-33.

WILLIAMSON, O. E. (2000). The new institutional economics: taking stock, looking ahead. Journal of Economic Literature, 38(3), pp. 595-613.

WILLIAMSON, O. E. (1993). Calculativeness, trust and economic organization. Journal of Law and Economics, 36(1), pp. 453-486.

WILLIAMSON, O. E. (1991). Comparative conomic organization: The analysis of discrete structural alternatives. Administrative Science Quarterly, 36, pp. 269-296.

WILLIAMSON, O. E. (1989). Transaction cost economics. Amsterdam: Elsevier Science.

WILLIAMSON, O. E. (1985). The Economic institutions of capitalism: firms, markets, relational contracting. London: Macmillan Free Press.

WILLIAMSON, O. E. (1975). Markets and hierarchies: analysis and antitrust implications. New York: Free Press.

ZYLBERSZTAJN, D. (2000). Economia das Organizações. In: ZYLBERSZTAJN, D.; NEVES, M. F. (Org). Economia e Gestão dos Negócios Agroalimentares. São Paulo: Pioneira.

ZYLBERSZTAJN, D. (1995). Estruturas de governança e coordenação do agribusiness: uma aplicação da nova economia das instituições. Tese (Livre-Docência) - Faculdade de Economia, Administração e Contabilidade, Universidade de São Paulo, São Paulo, SP, Brasil. 